\title{
MICROBIOTA E CONSERVAÇÃO DO LEITE
}

\author{
Microbiota and coservation of milk \\ Maria Fernanda Cáceres Menezes'; Caroline Posser Simeoni'; Mariana de Araújo Etchepare'; Katira Huer- \\ ta'; Débora Pererira Bortoluzzi'; Cristiano Ragagnin de Menezes². \\ 'Universidade Federal de Santa Maria (UFSM) - Aluna do mestrado do Programa de Pós - graduação de Ciência e Tecnologia dos Alimen- \\ tos. \\ ${ }^{2}$ UFSM - Prof. Adjunto do departamento de Tecnologia e Ciência dos Alimentosgmail.com
}

\section{Resumo}

O leite é constituído por uma série de componentes como água, lipídios, proteínas, carboidratos e micronutrientes que o tornam um importante substrato para a multiplicação dos microrganismos. A contaminação microbiana do leite pode se dar por duas vias: a endógena e a exógena, variando qualitativa e quantitativamente de acordo com as condições de higiene existentes. O leite cru, mantido sob temperatura de refrigeração por muitos dias, pode conter bactérias dos seguintes gêneros: Enterococcus, Lactococcus, Streptococcus, Leuconostoc, Lactobacillus, Microbacterium, Propionobacterium, Micrococcus, Proteus, Pseudomonas, Bacillus e Listeria; além de alguns representantes do grupo dos coliformes fecais. A microbiota do leite também é importante no que diz respeito à saúde pública, pois várias zoonoses importantes podem ser transmitidas ao homem por agentes etiológicos, presentes no leite cru ou mal pasteurizado. Para eliminar ou reduzir a níveis aceitáveis a microbiota do leite, os tratamentos térmicos são de fundamental importância. O objetivo desta revisão é analisar e discutir a influência da microbiota do leite no processamento e armazenamento do mesmo e os métodos de conservação utilizados para prolongar a vida de prateleira e garantir a segurança alimentar e a qualidade do produto final.

Palavras-chave: produtos lácteos, microrganismos, conservação.

\begin{abstract}
Milk contais a series of compounds such as water, lipids, proteins, carbohydrates and trace elements. Its nutricional characteristics makes it an important substratum for the multiplication of microorganisms. The microbial contamination of the milk can take in two ways: the endogenous and exogenous, ranging quantitatively and qualitatively according to the existing conditions of hygiene. Raw milk kept under refrigeration temperatures for many days can contain bacteria of the following genera: Enterococcus, Lactococcus, Streptococcus, Leuconostoc, Lactobacillus, Microbacterium, Oerskovia, Propionobacterium, Micrococcus, Proteus, Pseudomonas, Bacillus and Listeria. May also be present some representatives of the group of fecal coliform. To eliminate or reduce to acceptable levels the microbiota of milk, heat treatments are of fundamental importance The objective of this review was to analyze and discuss the influence of the microbiota of milk in processing and storing of milk and preservation methods used to prolong the shelf life and ensure food safety and product quality.
\end{abstract}

Key words: milk, microorganisms, preservation. 


\section{INTRODUÇÃO}

O leite é um alimento de grande importância na alimentação devido ao seu elevado valor nutritivo, como fonte de proteínas, lipídios, carboidratos, minerais e vitaminas, sendo por isso considerado um ótimo substrato para o crescimento de vários grupos de microrganismos, desejáveis e indesejáveis (SOUZA et al. 2009).

De acordo com Rezer (2010), a importância do leite sob o ponto de vista nutricional se deve a qualidade de suas proteínas, que são divididas em caseínas ( $\alpha 1, \alpha 2, \beta, \gamma$ e k) e proteínas do soro (albumina, $\alpha$-lactoalbumina, $\beta$-lactoglobulina, imunoglobulinas e proteose-peptonas), ao seu teor elevado em cálcio, fósforo, magnésio, vitamina $\mathrm{A}$, riboflavina e niacina.

As alterações microbianas que ocorrem no leite devem-se, principalmente, pela sua composição química variada. A contaminação microbiológica na indústria de alimentos representa um perigo para a saúde do consumidor, uma vez que o leite e os produtos lácteos podem veicular microrganismos associados a surtos de origem alimentar, além de ocasionar prejuízos econômicos (REZER, 2010).

A microbiota contaminante do leite normalmente é composta por bactérias, em especial pelas psicrotróficas, que se multiplicam no leite refrigerado, enquanto que leveduras e fungos são raramente encontrados (JAY, 2005).

De acordo com o Regulamento de Inspeção Industrial e Sanitária de Produtos de Origem Animal (RIISPOA), entende-se por leite, sem outra especificação, o produto oriundo da ordenha completa, e ininterrupta, em condições de higiene, de vacas sadias, bem alimentadas e descansadas. $\mathrm{O}$ leite de outros animais deve denominar-se segundo a espécie de que proceda (BRASIL, 1952).

Esta revisão pretende esclarecer, analisar e discutir a influência da microbiota no processamento e armazenamento do leite, assim como os métodos de conservação utilizados para prolongar a vida de prateleira, garantir a segurança alimentar e a qualidade do produto final.

\section{CONTAMINAÇÃO E HIGIENE NA ORDE- NHA}

Do ponto de vista tecnológico, os microrganismos de maior importância são os que contaminam o leite durante e após a ordenha. Santana et al. (2004) estudaram quatro propriedades da região de Londrina (PR), analisando diversos pontos do processo de produção do leite. Verificaram, desse modo, que os principais pontos de contaminação foram a água residual de latões, tanques de expansão e tetos higienizados inadequadamente. Isso demonstra a necessidade de se adotar boas práticas de higiene e limpeza na ordenha, que também contribuirão para reduzir as infecções mamárias dos animais, logo, se obter um leite de maior qualidade microbiológica e físico-química. Guerreiro et al. (2005) pesquisaram algumas propriedades leiteiras para observar as condições higiênicas durante e após a ordenha. Constataram que em todas as propriedades havia falhas nos procedimentos de higiene e limpeza, além de muitos animais estarem com mastite subclínica. Esse estudo sugere que os procedimentos de limpeza e higienização dos tetos (pré e pós-dipping), além de conferirem efeitos positivos sobre a qualidade do leite, diminuem a incidência de casos de mastite.

A mastite caracteriza-se por um processo inflamatório da glândula mamária acompanhado de danos ao epitélio glandular, o que reduz a produção de leite, altera a composição e eleva a contagem de células somáticas (CCS). Este processo normalmente é causado pela colonização de bactérias através do canal do teto, no entanto, fungos, leveduras e, mais raramente, vírus também podem estar etiologicamente envolvidos (SANTOS; FONSECA, 2007). As bactérias causadoras da mastite têm sido classificadas como contagiosas ou ambientais. Os organismos contagiosos são considerados adaptados à sobrevivência dentro do hospedeiro, em particular na glândula mamária, e são representados por Staphylococcus aureus e Streptococus agalactiae. Eles estabelecem infecções subclínicas, geralmente manifestadas pelo aumento na CCS, e a transmissão entre os animais ocorre no momento da ordenha (RADOSTITS; LESLIE; FETROW, 1994). Em contrapartida, os patógenos ambientais são descritos como oportunistas, não sobrevivem dentro do hospedeiro, desencadeiam a resposta imune e são eliminados. Os mais importantes são bactérias do grupo Enterobacteriacae (especialmente E. coli) e Streptococcus uberis. Já $S$. dysgalactiae pode comportar-se tanto como um patógeno contagioso quanto ambiental (RADOSTITS; LESLIE; FETROW, 1994).

De acordo com Tronco (2010), durante a higienização dos tetos, a lavagem com água não potável pode aumentar a contaminação, já que essa contém bactérias psicotróficas dos gêneros Pseudomonas, Aeromonas, e Alcaligenes. Outro tra- 
balho, desenvolvido por Brito, Brito e Verneque (2000), avaliaram a contaminação microbiana da superfície de tetos de vacas submetidas a diferentes condições de higienização pré-ordenha. Percebeu-se uma redução de mais de dez vezes do número de microrganismos da superfície dos tetos após a higienização com água potável, secagem com papel toalha e imersão em solução comercial à base de iodo. Esse procedimento simples contribui significativamente para a diminuição da contaminação microbiana no leite, já que a superfície dos tetos é reconhecida como um dos principais fatores de contaminação.

Uma maneira de monitorar a saúde do úbere e a qualidade do leite é avaliar a CCS (SCHUKKEN et al., 2003). Vários fatores como idade, ordem de parto, período de lactação, mês e estação do ano podem influenciar a variação da CCS de vacas em lactação, porém o estado de infecção é o principal fator responsável (HARMON, 1994). O limite de 200.000 células somáticas $/ \mathrm{mL}$ foi o mais indicado para estimar infecções intramamárias, parâmetro que pode ser utilizado para monitorar a dinâmica da mastite nos rebanhos leiteiros (SANTOS; FONSECA, 2007). Souza et al. (2009) observaram que os principais patógenos isolados de amostras de leite individuais, responsáveis pela maior elevação da CCS, foi $S$. agalactiae, $S$. aureus e outros Streptococcus spp. A elevação da CCS no leite acima de 200.000 células/mL acarreta mudanças nos componentes principais, como gordura, proteína e lactose, além de minerais e enzimas (SANTOS; FONSECA, 2007). No entanto, a legislação brasileira ainda permite até 480.000 células somáticas/ $\mathrm{mL}$ no leite cru refrigerado tipo A e até 600.000 células somáticas $/ \mathrm{mL}$ no leite cru refrigerado (BRASIL, 2011).

Além da CCS, a contagem bacteriana total (CBT) é outra análise utilizada para verificar a qualidade do leite. Nessa análise é feita a contagem do número de colônias presentes em uma amostra de leite, através de diluições decimais seriadas. O resultado final é expresso em UFC/mL e está relacionado tanto com a carga bacteriana inicial do leite, quanto com a taxa de multiplicação dos microrganismos durante o armazenamento. A contaminação microbiana do leite cru sofre influência de vários fatores, como saúde da glândula mamária, higiene de ordenha, ambiente em que a vaca fica alojada, boas práticas de ordenha, qualidade de água utilizada, assim como temperatura e tempo de armazenagem, sendo que esses últimos estão relacionados diretamente à taxa de multiplicação dos microrganismos presentes no leite (SANTOS;
FONSECA, 2007).

A legislação brasileira passou por melhorias, mas ainda é considerada pouco exigente quanto à qualidade microbiológica do leite, pois, de acordo com Jay (2005), quando a contagem bacteriana total exceder a $105 \mathrm{UFC} / \mathrm{mL}$, indica que o leite foi obtido em condições higiênico-sanitárias insatisfatórias. Atualmente a CBT permitida pela legislação é de 1 x104 UFC/mL para leite cru refrigerado tipo A, $1 \times 103 \mathrm{UFC} / \mathrm{mL}$ para leite pasteurizado tipo A e 6x105 UFC/mL para leite cru refrigerado (BRASIL, 2011).

O leite de tanque de uma plataforma leiteira foi analisado, por Brito et al. (1998), para verificação da prevalência dos agentes contagiosos da mastite em rebanhos leiteiros e determinação de células somáticas. Dos 33 rebanhos amostrados na plataforma de recepção, $27(81,2 \%)$ apresentaram contagens de células somáticas acima de 200.000 células somáticas $/ \mathrm{mL}$, que puderam ser relacionadas com processo inflamatório infeccioso confirmado pela CBT, na qual foram isolados agentes da mastite em 29 dos 33 rebanhos. Em nove deles $(27,3 \%)$ isolaram-se concomitantemente $S$. aureus e S. agalactiae, em $17(51,5 \%)$ isolou-se somente $S$. aureus e em três $(9,1 \%)$ somente $\mathrm{S}$. agalactiae. Estes resultados demonstram que há uma correlação significativa entre a CCS e a CBT, e que, quando estas contagens estão acima dos padrões permitidos, indicam que a qualidade microbiológica e físico-química do leite não é ideal.

Um estudo, desenvolvido por Bozo et al. (2013), buscou adequar a qualidade do leite cru aos parâmetros estabelecidos pela legislação brasileira por meio da implantação de boas práticas de ordenha, melhorias no manejo e no tratamento de animais e também na manutenção dos equipamentos. Antes da adoção dessas medidas a média de CBT das propriedades avaliadas era de 1,36 x 106 $\mathrm{UFC} / \mathrm{mL}$. Após a implantação das boas práticas de ordenha, a CBT reduziu para 4,7 x 104 UFC/ $\mathrm{mL}$, atingindo os requisitos estabelecidos pela legislação quanto à qualidade microbiológica de leite cru refrigerado. Estes resultados demonstram a importância e a necessidade da adoção de boas práticas de ordenha, a fim de reduzir a contaminação microbiana e aumentar a qualidade do leite.

É importante lembrar que, por mais higiênica que seja a ordenha, é pouco provável termos um leite livre de microrganismos. Porém é possível controlar a multiplicação microbiana, já que esta prejudica a qualidade do leite, prejudica o processamento da matéria prima e reduz o tempo de prateleira do leite e seus derivados, além de colocar 
em risco a saúde do consumidor. Esse controle pode ser feito primeiramente através da refrigeração, uma vez que a maioria dos microrganismos do leite é mesófila. Dessa forma o resfriamento de 0 a $4^{\circ} \mathrm{C}$ deve ser feito o mais rápido possível (BRASIL, 2011; BEHMER, 1999).

Segundo Fonseca (1998), a temperatura e o tempo de armazenamento são muito importantes, uma vez que estes dois fatores estão diretamente ligados com a multiplicação dos microrganismos presentes no leite, afetando diretamente a contagem bacteriana total. A temperatura e o período de armazenamento antes da pasteurização determinam, de maneira seletiva e pronunciada, a intensidade de desenvolvimento das diversas espécies microbianas contaminantes. O leite, quando é obtido por ordenha mecânica e refrigerado a $4^{\circ} \mathrm{C}$, apresenta qualidade microbiológica satisfatória se comparado aos padrões exigidos internacionalmente. Isto porque a baixa temperatura inibe ou reduz a multiplicação da maioria das bactérias e diminui a atividade de enzimas degradativas. Portanto, a obtenção do leite de vacas sadias e em condições higiênicas adequadas, e o seu resfriamento imediato a $4^{\circ} \mathrm{C}$ são medidas fundamentais para garantir a qualidade e a segurança do leite e seus derivados (ARCURI et al., 2006)

Estudos sobre contagem bacteriana apontam que os principais problemas de contaminação são em decorrência da deficiência na limpeza e sanitização dos equipamentos de ordenha, falta de higiene do ordenhador e resfriamento inadequado do leite (TRONCO, 2010). Mhone, Matope e Petronella (2011), em um estudo realizado em propriedades leiteiras no Zimbábue, perceberam que as amostras que tinham maior CBT eram as que estavam mais distantes dos postos de refrigeração. Foi possível estabelecer uma correlação positiva entre o intervalo de tempo da ordenha e da refrigeração e a contagem bacteriana total.

Diversos fatores referentes à infraestrutura, ordenha, limpeza dos equipamentos e utensílios, sanidade e nutrição animal foram analisados em propriedades produtoras de leite localizadas na cidade de Barbosa Ferraz (PR). Nas 17 propriedades estudadas, cinco itens não estavam em conformidade com as práticas de higiene recomendadas. Essas práticas consistem na realização do teste da caneca de fundo preto, que é feita com os três primeiros jatos de leite e é utilizada para detectar mastite clínica através da visualização de grumos no leite. Pré-dipping e pós- dipping, que correspondem à desinfecção dos tetos antes e após a ordenha, respectivamente. Secagem dos tetos com papel toalha após a lavagem e a manutenção dos animais em pé após a ordenha, para evitar contaminações provenientes do solo, uma vez que os ductos lactíferos dos tetos ainda se encontram abertos (GUIDO et al., 2010). Os dados obtidos indicam que ainda existe um grande desafio a ser enfrentado pelos produtores de leite para adequarem-se às normas estabelecidas por legislação (OLIVEIRA; FONSECA; GERMANO, 1999).

O pagamento do leite baseado na qualidade do mesmo representa uma medida de incentivo adequada para estimular o produtor a adotar práticas em prol da melhoria da qualidade do leite produzido. Contudo, há quem defenda que a situação mudará somente se o produtor que não atender as exigências de qualidade seja penalizado. Um exemplo disso são os programas de pagamento de leite baseados em critérios de bonificação e penalização, conforme a qualidade do leite (BULLETIN, 2006). Contudo, para que funcionem, essas medidas deveriam ser adotadas por todos os laticínios, pois na prática alguns exigem qualidade e outros demonstram um total desinteresse na melhoria da qualidade do leite.

\section{ALTERAÇÕES E DETERIORAÇÃO DO LEITE}

Segundo Tronco (2010), o leite é composto de $87,3 \%$ de água e $12,7 \%$ de sólidos totais. Os sólidos totais são divididos em 3,6\% de gordura e $9,1 \%$ de extrato seco desengordurado. Este compreende as proteínas $(3,3 \%)$, a lactose $(4,9 \%)$ e os minerais $(0,9 \%)$. O leite contém vitaminas lipossolúveis $\mathrm{A}, \mathrm{D}, \mathrm{E}$ e $\mathrm{K}$, que ficam suspensas na gordura, e as hidrossolúveis B1, B2 e C e os sais minerais presentes encontram-se em dissolução, sendo os principais: cálcio, sódio, potássio e magnésio. O leite e seus derivados representam uma das principais fontes de proteína e cálcio da população brasileira (ÁLVARES; BERNARDES; NETTO 2002). Segundo o Regulamento Técnico de Identidade e Qualidade de Leite, o leite cru resfriado deve apresentar os seguintes requisitos mínimos de qualidade dentro da propriedade rural: densidade entre 1,028 e $1,032 \mathrm{~g} / \mathrm{mL}$; o ponto crioscópico máximo $0,512^{\circ} \mathrm{C}$; acidez titulável entre 14 e $18^{\circ} \mathrm{D}$; além destas a gordura não deve ser inferior a $3 \mathrm{~g} / 100 \mathrm{~g}$, e proteína não deve ser inferior a 2,9 g/100g (BRASIL, 2011).

As alterações do leite ocorrem principal- 
mente através da ação microbiana sobre os seus constituintes básicos: carboidratos, proteínas e lipídeos. A lactose é um dos carboidratos de maior fonte energética dos microrganismos que, quando utilizada, decompõe-se em ácido lático, sendo essa transformação denominada de fermentação lática. Esse por sua vez atua sobre a caseína, produzindo a coagulação do leite. Geralmente leites ácidos e coagulados não são aceitos nas indústrias, pois essas características indicam grande contaminação bacterina proveniente da falta de higiene na ordenha e de falhas nas boas práticas de fabricação (EVANGELISTA, 1987; BEHMER, 1999).

Microrganismos proteolíticos, como Bacillus sp., Proteus sp. e Pseudomonas sp. podem degradar a caseína, resultando em peptídeos que ainda podem ser decompostos a aminoácidos, originando assim a fermentação proteolítica, enquanto que microrganismos lipolíticos, como Pseudomonas fluorescens e Achromobacter lipolyticum, hidrolisam a gordura do leite a glicerol e ácidos graxos, sendo denominada de fermentação butírica (FOSCHIERA, 2004; PELCZAR; CHAN; KRIEG, 1997). A fermentação pela qual se produz ácido propiônico e, secundariamente, ácido acético e gás carbônico é denominada de fermentação propiônica, e a bactéria responsável por esse tipo de alteração é do gênero Propionibacterium (BEHMER, 1999).

Poucas indústrias de alimentos são tão dependentes da qualidade de sua matéria-prima quanto à de laticínios. Não há como melhorar a qualidade de um leite que chega à plataforma da indústria após sofrer algum tipo de deterioração. A única forma de se obter produtos lácteos seguros para a saúde pública é a utilização de matéria-prima de boa qualidade (DÜRR, 2002).

Nem todos os microrganismos causam deterioração no leite, existem alguns microrganismos conhecidos como bactérias láticas, como as do gênero Lactobacillus, que atuam beneficamente sobre as características do leite e de produtos lácteos. São utilizadas no processo tecnológico como culturas starters, pois produzem ácido lático a partir da lactose, participam do processo de maturação de queijos, produzem diacetil e acetaldeído, que conferem aroma e sabor característico aos produtos (ORDOÑEZ, 2005). Espécies desse gênero podem ser homofermentativas, produzindo mais de $85 \%$ de ácido láctico a partir da glicose, ou heterofermentativas, produzindo ácido láctico, $\mathrm{CO} 2$, etanol e/ou ácido acético. A temperatura ótima de crescimento é de $27^{\circ} \mathrm{C}$ a $40^{\circ} \mathrm{C}$ e são acidúricos, crescem em pH 4,5 (SILVA; JUNQUEIRA; SILVEIRA,
2007). Linhagens de L. acidophilus podem também melhorar o valor nutricional dos produtos aos quais forem adicionados, por serem capazes de sintetizar ácido fólico, niacina, riboflavina e vitamina $\mathrm{K}$, sendo a espécie mais comumente empregada em derivados lácteos (GOMES; MALCATA, 1999).

Além disso, muitas bactérias láticas são consideradas e utilizadas como probióticos, ou seja, microrganismos vivos que, quando ingeridos em quantidades adequadas, conferem benefícios a saúde do hospedeiro (ANAL; SINGH, 2007; BRASIL, 2008). Muitos estudos clínicos têm demonstrado a eficácia terapêutica e profilática de probióticos específicos contra gastrenterite viral aguda, diarréia associada a antibióticos, infecção por Clostridium difficile e por Helicobacter pylori, doença intestinal inflamatória e síndrome do intestino irritado, além de contribuir com a redução dos sintomas de intolerância à lactose, a inibição de microrganismos patogênicos, produção de vitaminas e a redução dos níveis de colesterol (GILL, 2003).

\section{FLORA MICROBIANA E SEU IMPACTTO NA QUALIDADE DO LEITE E NA SAÚDE PÚBLICA}

A flora bacteriana do leite pode variar consideravelmente em número e espécie, dependendo de sua origem e do grau de contaminação. O leite, ao ser sintetizado e secretado nos alvéolos da glândula mamária de uma vaca saudável, é estéril, mas ao ser retirado, manuseado e armazenado pode se contaminar com microrganismos originários do interior da glândula mamária, da superfície dos tetos e do úbere, dos equipamentos de ordenha e de armazenamento e de várias fontes ambientais (BRITO; ARCURI; BRITO, 2000).

Segundo Tronco (2010), a contaminação do leite pode processar-se por duas vias: a endógena (no caso de animais enfermos) e a exógena (após a saída do úbere). Estas contaminações podem atingir a ordem de milhões de bactérias por mililitros $(\mathrm{mL})$, podendo incluir tanto microrganismos patogênicos como deteriorantes. Desta forma, a saúde da glândula mamária, a higiene de ordenha, o ambiente em que a vaca fica alojada, os procedimentos de limpeza dos equipamentos de ordenha, a higiene do ordenhador e dos tanques de resfriamento são fatores que afetam diretamente a qualidade microbiológica do leite cru.

$\mathrm{O}$ interior do úbere do animal, mesmo saudável, apresenta bactérias que contaminam o 
leite no momento da ordenha. A carga original é reduzida e consiste principalmente em bactérias gram positivas como Micrococcus spp., Corynebacterium spp. e de Streptococcus spp., mas também pode haver bactérias gram negativas e esporuladas, em taxas que geralmente não ultrapassam a $10 \%$. No entanto, se o animal estiver doente, os microrganismos podem atingir o úbere por via endógena, como no caso de Mycobacterium bovis e Brucella abortus. Se o animal estiver com mastite, o úbere estará colonizado por uma grande quantidade de bactérias, que, no momento da ordenha, contaminarão o leite e os equipamentos de ordenha (ORDOÑEZ, 2005).

O tipo e a carga microbiana inicial, juntamente com a temperatura de armazenamento do leite, são parâmetros que influem a proliferação das bactérias durante o armazenamento do leite em estado cru. A microbiota lática e os coliformes são os mais abundantes na temperatura de 25 a $30^{\circ} \mathrm{C}$, por isso é imprescindível a refrigeração à $4^{\circ} \mathrm{C}$ para inibir a multiplicação dos microrganismos mesófilos. Em contrapartida, as bactérias psicrotrófica, em especial as aeróbias gram negativas como Pseudomonas spp., podem proliferar-se em temperatura de refrigeração (JAY, 2005).

O leite cru, mantido sob temperaturas de refrigeração por muitos dias, pode apresentar bactérias dos seguintes gêneros: Enterococcus, Lactococcus, Streptococcus, Leuconostoc, Lactobacillus, Microbacterium, Propionobacterium, Micrococcus, Proteus, Pseudomonas, Bacillus e Listeria, assim como alguns representantes do grupo dos coliformes (JAY, 2005).

Zeni et al. (2013) verificaram a incidência de microrganismos psicrotróficos e mesófilos no leite cru destinado à produção de leite UHT. As amostras de leite cru refrigerado mostraram contagens para mesófilos e psicrotróficos acima de 106 UFC. Essas bactérias secretam e excretam enzimas proteolíticas e lipolíticas termorresistentes, que causam alterações físico-químicas e sensoriais no leite cru ou mesmo depois de processado termicamente. Observou-se que a alta contagem inicial de microrganismos psicrotróficos teve relação desfavorável com o tempo de vida de prateleira do leite UHT.

O gêmero Pseudomonas faz parte do grupo de bactérias psicrotróficas, que são capazes de se reproduzir durante o período de refrigeração e armazenamento na indústria. P. fluorescens é a principal bactéria responsável pela produção de proteases e lipases termorresistentes, responsáveis pela deterioração de produtos lácteos industriali- zados, especialmente leites UHT. Já P. aeruginosa, está envolvida com processos de mastite ambiental (COSTA et al., 2002).

A família Enterobacteriaceae compreende os gêneros Escherichia, Edwardsiella, Citrobacter, Salmonella, Shigella, Klebsiela, Enterobacter, Serratia, Proteus e Yersinia. Esses microrganismos são bacilos gram negativos, anaeróbios facultativos e sensíveis à alta temperatura, sendo destruídos na pasteurização do leite. Em condições favoráveis E. coli pode alterar as características do leite e da maioria dos produtos lácteos, uma vez que fermenta a lactose e outros carboidratos produzindo ácido lático, ácido acético, $\mathrm{CO} 2$ e H2. Coliformes termotolerantes, como E.coli, são indicadores de contaminação fecal e sua presença pode ser relacionada com bactérias patogênicas. A contaminação do leite com esses microrganismos se dá tanto por secreção intramamária, quanto por contaminação fecal do úbere ou de equipamentos de ordenha (LAVEN; ASHMORE; STEWART, 2003). Van Kessel et al. (2002) encontraram que apenas 7\% das 861 amostras de leites analisadas não estavam contaminadas com coliformes termotolerantes. Resultados semelhantes foram encontrados por Tebaldi et al. (2008), onde 6,25\% das amostras não apresentavam coliformes termotolerantes.

Outra família de bactérias que faz parte da microbiota do leite é a Micrococcaceae. Os principais representantes são Micrococcus spp. e Staphylococcus spp., que são cocos gram positivos, geralmente imóveis, aeróbios ou anaeróbios facultativos. Micrococcus varians é um contaminante não patogênico muito comum no leite e em produtos lácteos. Por outro lado, S. aureus, quando presente em concentrações maiores que $105 \mathrm{UFC} / \mathrm{mL}-1$, aumenta os riscos de produção de enterotoxinas estafilocócicas termoestáveis, podendo provocar intoxicação alimentar. Além disso, a presença desse microrganismo pode refletir problemas de sanidade do rebanho, como a presença de mastite subclínica (TEBALDI et al., 2008).

Streptococcus, Leuconostoc e Pediococcus são cocos gram positivos, anaeróbios facultativos, membros da família Streptococcaceae e comumente encontrados no leite. $S$. dysgalactiaee e $S$. agalactiae têm sido encontrados no leite e no tecido mamário de vacas com mastite. Leuconostoc mesenteroides habitualmente produz viscosidade característica no leite, à temperatura de $20-25^{\circ} \mathrm{C}$, causando deterioração do produto (JAY, 2005).

Bacillus spp. e Clostridium spp. são bacilos gram positivos esporulados, termorresistentes, aeróbios e anaeróbios respectivamente. $B$. subtilis 
é uma das bactérias mais frequentemente encontrada no leite, pois pode resistir ao processo de pasteurização. Está associada com a produção de viscosidade e coagulação do leite cru ou pasteurizado (JAY, 2005). Bacillus cereus também é um microrganismo termodúrico que pode apresentar atividade lipolítica e proteolítica, comprometendo a qualidade de produtos lácteos. Maziero et al. (2011) avaliaram a presença de $B$. cereus em 110 amostras de leite UHT. Destas, $16,36 \%$ (18 amostras) foram positivas, no entanto não excederam os padrões permitidos por legislação. Todas as cepas de $B$. cereus isoladas apresentaram atividade proteolítica após $24 \mathrm{~h}$ de incubação e 44,4\% apresentaram atividade lipolítica e proteolítica simultaneamente. Foi concluído nesse estudo que a presença de $B$. cereus proteolítico e lipolítico em leite UHT pode causar defeitos sensoriais e diminuir a vida de prateleira do leite. Em outro estudo, realizado na Índia, concluiu-se que a porcentagem de contaminação por B. cereus no leite esta em torno de 16 a $50 \%$ (SHAH; WADHER; REDDY, 1996).

Moraes (2005) pesquisou o desenvolvimento de microrganismos potencialmente patogênicos que podem comprometer a qualidade e a segurança do leite e seus derivados. O presente estudo foi realizado em 42 propriedades leiteiras no estado do Rio Grande do Sul, nas quais foram coletadas 116 amostras para estimar a qualidade microbiológica do leite in natura. A presença de coliformes fecais e $E$. coli foi confirmada em 24 amostras, de oito propriedades. Não foi detectada a presença de Salmonella. As amostras analisadas estavam dentro dos padrões exigidos pela legislação para microrganismos mesófilos e psicrotróficos, porém alguns autores citam que contagens acima de $103 \mathrm{UFC} / \mathrm{mL}$ podem ser prejudiciais ao processamento de laticínios.

Doenças zoonóticas como brucelose, difteria, febre Q, salmonelose, colibacilose, listeriose, campilobacteriose, mycobacteriose e iersiniose podem ser transmitidas pelo leite e, devido ao aumento da incidência, estão sendo classificadas como doenças emergentes transmitidas por alimentos (SANTOS; FONSECA, 2007).

Silva (2006) pesquisou a presença de Listeria spp. em 48 pontos de seis indústrias de laticínios localizadas no estado do Rio de Janeiro, incluindo tanques de fabricação de queijos, parede, piso, prateleiras, ralos, superfícies de câmara fria e mesa de enformagem. Em cada um dos pontos foram coletadas duas amostras através do método de swab, totalizando 94 amostras. Nenhuma amostra foi positiva para Listeria spp. nos testes fenotípicos e sorológicos.

Bactérias pertencentes ao gênero Brucella causam uma enfermidade zoonótica grave em humanos. Os indivíduos adquirem essa doença consumindo alimentos contaminados, principalmente leite cru. Foram analisadas 181 amostras para Brucella sp. e, destas, dez amostras, de três propriedades distintas, foram positivas. Este trabalho indica que o leite pode representar um risco à saúde pública (MORAES, 2005).

Mycobacterium bovis, agente causador da tuberculose bovina, também é uma zoonose potencial e pode acometer humanos. A transmissão desse agente, dos animais para o homem, ocorre através do consumo de leite contaminado, cru ou mal pasteurizado. Estima-se que o consumo de leite cru seja responsável por quatro mil novos casos de tuberculose por ano no Brasil (VASCONCELLOS, 2006). Estudos feitos na Tanzânia demostraram que entre 1995 e 2009 houve um aumento significativo de casos de tuberculose extrapulmonar, e os isolados humanos de M. bovis tinham 70 a $80 \%$ de relação genética aos encontrados em bovinos, indiscutivelmente, sugerindo uma relação evolutiva e de infecção entre eles (KAZWALA et al., 2001). Nos países em desenvolvimento, a infecção por M. bovis em humanos também está aumentando, devido à falta de controle na pasteurização de leite (ETTER et al., 2006). Kazwala et al., (1998) analisou 805 amostras de leite e, destas, 31 foram positivas para micobactérias, sendo que $6,5 \%$ foram identificadas como M. bovis. Esses resultados mostram, mais uma vez, que o consumo de leite cru é uma ameaça à saúde pública e que o tratamento térmico é fundamental.

Segundo a legislação brasileira, vacas positivas para brucelose e tuberculose não podem ser ordenhadas e devem ser descartadas do rebanho (BRASIL, 1952). Além disso, a instrução normativa ${ }^{\circ} 62$ do MAPA determina que todo rebanho leiteiro tenha controle rigoroso de brucelose e tuberculose, cumprindo normas e procedimentos de profilaxia e saneamento, com o objetivo de obter o certificado de propriedade livre destas enfermidades, em conformidade com o Programa Nacional de Erradicação da Brucelose e Tuberculose (BRASIL, 2011).

As leveduras também podem causar alterações em muitos derivados lácteos, como queijos e cremes destinados a fabricação de manteiga, por sua ação sobre a lactose, resultando na produção de $\mathrm{CO} 2$ e originando um mau odor pelo processo fermentativo. A qualidade do leite pode ainda ser afetada pelas enzimas produzidas por esses 
microrganismos, dentre elas, destacam-se as proteases e as lipases (JAY, 2005). Além da deterioração de produtos lácteos, as leveduras também são capazes de causar várias infecções no homem e animais (VASCONCELLOS, 2006).

Por outro lado, as leveduras isoladas de leite cru têm sido utilizadas como cultura starter em produtos lácteos como, por exemplo, o queijo. Uma cultura de starter pode proporcionar características particulares ao produto devido à fermentação controlada e previsível. Estas leveduras podem também mostrar um efeito benéfico sobre a qualidade de produtos lácteos, pois podem inibir ou eliminar

microrganismos indesejáveis e contribuir para o processo de maturação (SPANAMBERG et al., 2004).

Spanamberg et al. (2004) verificaram a diversidade de espécies de leveduras e fungos isolados a partir de leite cru, coletadas em 25 propriedades leiteiras de cinco cidades do sul do Brasil. Das 36 amostras analisadas foram obtidos 80 isolados. Entre eles foram identificados os gêneros Cândida, Cryptococcus, Debaryomyces, Dekkera, Geotrichum, Kluyveromyces, Pichia, Rhodotorula, Sporidiobolus, e Trichosporon, sendo que, em torno de, $79 \%$ apresentaram atividade enzimática e lipolítica e $6 \%$ proteolítica. Este estudo demonstrou que a variedade de leveduras associadas ao leite é grande e, mesmo que estes microrganismos não sobrevivam aos tratamentos de pasteurização e esterilização, aplicados durante o processamento do leite, sua atividade enzimática pode alterar os componentes do leite e afetar sua qualidade.

As leveduras encontradas no leite apresentam um crescimento em torno de 101 a 103 $\mathrm{UFC} / \mathrm{mL}$, contudo o seu desenvolvimento no leite durante o armazenamento refrigerado é limitado, pois elas são rapidamente inibidas por bactérias psicrotróficas (CLETUS KURTZMAN; FELL; BOEKHOUT, 2011).

Ao contrário da maioria dos agentes microbiológicos, os vírus são parasitas intracelulares, logo, não se multiplicam nos alimentos e o nível de contaminação não aumenta durante o armazenamento. Entretanto, os vírus podem sobreviver por longos períodos nos alimentos e o leite pode veicular esses microrganismos (KOOPMANS; DUIZER, 2004). A fonte de infecção pode ser o próprio animal, contaminando o leite por secreções ou fezes (BAERT; DEBEVERE; UYTTENDAELE, 2009). Geralmente esses agentes são raros em indústrias de laticínios e podem ser controlados com uma boa higiene do úbere pré e pós ordenha (HILLERTON et al., 2001). Poucos gêneros de vírus são capazes de causar alterações nos produtos de origem láctea e estes gêneros são: Poxyvirus, Enterovirus, Flavovirus, vírus da hepatite e bacteriófagos (TRONCO, 2010).

Os vírus estão cada vez mais atrelados com surtos de doenças transmitidas por alimentos. $\mathrm{Na}$ Europa, os agentes virais foram responsáveis por $10,2 \%$ dos surtos de origem alimentar em 2006 e foram apontados como o segundo agente mais comum, depois da Salmonella. Foi estimado que a cada ano, nos EUA, 67 \% dos casos de gastroenterites agudas de origem alimentar são atribuídas aos vírus. O norovírus, vírus da hepatite $\mathrm{A}$, rotavírus, astrovírus e adenovírus entéricos foram descritos como vírus de origem alimentar (BAERT, DEBEVERE, UYTTENDAELE, 2009).

Produtos frescos podem ser considerados como alimentos veiculadores de alto risco. Durante o processamento dos alimentos, a falta de boas práticas de higiene de manipuladores infectados pode gerar a contaminção do leite. Dessa forma, qualquer alimento manipulado que não sofra processamento térmico representa risco á saúde do consumidor (BAERT, DEBEVERE, UYTTENDAELE, 2009). No entanto, o processo de pasteurização é capaz de destruir os vírus, inclusive o vírus da febre aftosa (WALSTRA; WOUTERS; GEUTERS, 2006).

\section{CONSERVAÇÃO DE LEITE}

Teoricamente, o melhor método de conservar o leite e aumentar sua vida útil seria submeter esse produto a um tratamento capaz de destruir todos os microrganismos presentes, inativar todas as enzimas, mantendo todas as características desse leite (TRONCO, 2010). Na maioria dos países o tratamento do leite se dá apenas por processamento térmico, pois a aplicação de altas temperaturas tem efeito no metabolismo dos microrganismos, causando desnaturação de proteínas e inativação de enzimas (FRANCO et al., 2008).

A pasteurização consiste no emprego conveniente do calor, com o fim de destruir totalmente a flora microbiana patogênica sem alteração sensível da constituição física e do equilíbrio do leite, sem prejuízo dos seus complementos bioquímicos, assim como de suas propriedades organolépticas normais (BRASIL, 1952). O principal objetivo desse tratamento térmico é a destruição total de microrganismos patogênicos do leite e da maior 
parte da flora saprófita, o que é fundamental para preservação da qualidade do leite durante o armazenamento (FRANCO et al., 2008; TRONCO, 2010). No entanto, esse tratamento não é capaz de destruir bactérias formadoras de esporos (VARNAM; SUTHELAND, 1995).

Podemos separar a pasteurização, classicamente, em LTLT (Low Temperature Long Time) ou pasteurização lenta em HTST (High Temperature Short Time) ou pasteurização rápida em placas (FRANCO et al., 2008; TRONCO, 2010).

De acordo com o artigo 157 da RIISPOA, a pasteurização lenta consiste no aquecimento do leite de 62 a $65{ }^{\circ} \mathrm{C}$ por 30 minutos, já a pasteurização rápida consiste no aquecimento do leite em camada laminar de 72 a $75^{\circ} \mathrm{C}$ por 15 a 20 segundos, em aparelhagem própria (BRASIL, 1952). Ambos tratamentos são capazes de destruir leveduras, bolores, bactérias gram-negativas e gram-positivas, além de microrganismos patogênicos não formadores de esporos, como Mycobacterium tuberculosis, Brucella abortus, Listeria monocytogenes e Coxiella brunetti (FRANCO et al., 2008).

$\mathrm{Na}$ pasteurização lenta o leite é aquecido até a temperatura indicada, em tanques de parede dupla com camisa de vapor, mantido sobre agitação mecânica constante durante todo processo, a fim de facilitar troca de calor. Após, o leite deve ser resfriado rapidamente, através da circulação de água fria. Esse sistema conserva as propriedades do leite, aproximando-as do estado in natura, porém, é um processo demorado e requer grande quantidade de calor e frio, tornando o tratamento bastante caro (TRONCO, 2010). Entretanto, esse tipo de pasteurização não é contemplado na instrução normativa ${ }^{\circ} 62$ de 29 de dezembro de 2011 para leite de consumo, mas pode ser usado para alguns derivados (TRONCO, 2010; BRASIL, 2011).

A pasteurização rápida, também conhecida como pasteurização em placas, é feita em um equipamento com um grupo de placas retangulares onduladas posi, com espaço de circulação entre si, por onde o leite irá passar. O pasteurizador em placas é composto de três seções: seção de aquecimento, seção de resfriamento e seção de regeneração ou troca (TRONCO, 2010).

Embora esse processo seja eficiente na eliminação de formas vegetativas de diversos microrganismos, a pasteurização HSHT não é capaz de eliminar esporos termorresistentes. Isso foi confirmado em um estudo realizado por Lin et al. (1998), no qual amostras de leite foram avaliadas em diversos estágios de processamento e verificou-se que esporos de Bacillus cereus estão presentes no leite pasteurizado.

Além da pasteurização, outras técnicas que podem ser usadas para reduzir, ou mesmo eliminar, microrganismos no leite e derivados são: esterilização, microfiltração, irradiação, bactofugação, entre outras (TRONCO, 2010). O uso de conservantes no leite é proibido pela legislação brasileira e considerado fraude (BRASIL, 1952).

O processo de esterilização leva a destruição de todas as células viáveis que possam ser contadas por técnicas de semeadura. No caso de alimentos, usa-se o termo "esterilização comercial" para indicar que, após esse tratamento térmico, nenhum microrganismo poderá ser detectado por métodos usuais de semeadura ou, então, que o número de sobreviventes é tão baixo que pode ser considerado insignificante (FRANCO et al. 2008).

A esterilização por UHT (Ultra High Temperature), ou ultrapasteurização, consiste na conservação de alimentos líquidos após uma exposição breve a altas temperaturas. O produto obtido é bacteriologicamente estéril e deve manter as características nutricionais e organolépticas do produto inicial, possuindo uma vida de prateleira de mais de seis semanas. O processo envolve aquecimento do leite, previamente homogeneizado, de 135 a 150 ${ }^{\circ} \mathrm{C}$ durante 2 a 4 segundos (processo térmico de fluxo contínuo) e, após, resfriamento do produto (FRANCO et al. 2008; TRONCO, 2010).

A esterilização pode ocorrer por aquecimento direto, onde há mistura do vapor com o leite, ou por aquecimento indireto, onde o agente térmico não se mistura com o leite, mas é transferido por parede metálica (TRONCO, 2010; VARNAM; SUTHELAND, 1995). Após o tratamento de esterilização, o produto não necessita receber refrigeração enquanto fechado, no entanto deve-se salientar que para manter as condições microbiológicas proporcionadas pelo processo de esterilização, o envasamento do leite UHT deve ser asséptico (VARNAM; SUTHELAND, 1995).

As novas tecnologias para o processamento de leite, pesquisadas por diversos autores, incluem a microfiltração (MF), campos elétricos pulsados (CEP), ultrassom e alta pressão hidrostática (WALKING-RIBEIRO et al. 2011).

O campo elétrico pulsado de alta intensidade (CEP) é um processo não térmico que consiste na aplicação de pulsos de alta tensão $(20-80 \mathrm{kV} /$ $\mathrm{cm}$ ) dispendidos por dois eletrodos que circundam o alimento. Esta tecnologia é capaz de inativar os microrganismos e as enzimas presentes (responsáveis por alterações indesejáveis), garantindo ao consumidor um alimento seguro e de qualidade 
(RIVAS, 2010). O tratamento por CEP é conduzido durante menos de 1 s e a perda de energia é mínima devido a um aquecimento rápido e uniforme do alimento (RIVAS, 2010; VEGA-MERCADO et al. 2007). Sua ação nos microrganismos ocorre pela formação de poros nas membranas celulares, promovendo a ruptura das células após a exposição ao CEP (VEGA-MERCADO et al. 2007). Ainda, Vega-Mercado et al. (2007) descreveram que os fatores que influenciam a inativação microbiana por CEP incluem a temperatura de tratamento, o $\mathrm{pH}$, a força iônica a condutividade do alimento, e intensidade, o número e a duração dos impulsos elétricos aplicados no produto.

Uma das vantagens da utilização da tecnologia de CEP, em relação aos métodos térmicos tradicionais, é a baixa quantidade de calor produzido. Como resultado do ligeiro aumento de temperatura durante o processamento, o alimento mantém as características físicas, químicas e nutricionais e, ainda, apresenta uma vida de prateleira satisfatória. As principais aplicações do CEP incluem a pasteurização de sucos de frutas e tratamento de leite e produtos lácteos (RIVAS, 2010).

Walking-Ribeiro et al. (2011) realizaram um estudo comparando as diferentes metodologias de conservação de alimentos: CEP, MF, combinação de $\mathrm{PEP} / \mathrm{MF}$ e pasteurização térmica (PT), e avaliaram seus efeitos na redução da carga microbiana do leite. A amostra de leite cru foi utilizada como inóculo para o enriquecimento do leite desnatado antes dos tratamentos. A vida de prateleira do leite tratado com $\mathrm{PEP} / \mathrm{MF}$, armazenado a $4^{\circ} \mathrm{C}$, foi monitorada ao longo de 35 dias e microrganismos aeróbicos totais, enterobactérias, bolores e leveduras, lactobacilos, psicrotróficos, psicrotróficos termodúricos, termófilos e estafilococos foram analisados durante esse período. Já o leite tratado com PT foi monitorado durante sete dias. Os resultados deste estudo demonstraram que o tratamento combinado de $\mathrm{PEF} / \mathrm{MF}$ foi mais eficaz, pois promoveu maior inativação microbiana e estabilidade durante o armazenamento do produto, representando uma alternativa viável de conservação do leite.

A alta pressão hidrostática (APH) é um método de pasteurização a frio utilizado para prolongar a vida de prateleira e reduzir o número de patógenos, aplicado a produtos sólidos ou líquidos, embalados ou não. São empregados 100 a 1.000 Mega Pascal (MPa) de pressão, a temperaturas oscilando de 0 a $110^{\circ} \mathrm{C}$ e por tempos de um milisegundo a mais de vinte minutos. A compressão aumenta a temperatura de um produto, adiabati- camente, $3^{\circ} \mathrm{C}$ para cada $100 \mathrm{Mpa}$. Esta tecnologia pode inativar as células vegetativas microbianas através do rompimento das ligações não covalentes, causando danos na membrana celular bacteriana; é capaz de interferir nas estruturas secundárias e terciárias das proteínas e dos polissacarídeos, alterando a sua estrutura e integridade funcional de acordo com intensidade da pressão empregada (BRODY; MORRIS; WICKER, 2007). Os esporos, no entanto, tendem a ser extremamente resistentes a APH, em comparação com as células vegetativas, suportando mais de $1000 \mathrm{MPa}$ (CONSIDINE et al., 2008).

Para produtos lácteos utiliza-se pressões de $400 \mathrm{MPa}$ a $600 \mathrm{MPa}$, por períodos de 1 a 5 minutos. Ao contrário do processo térmico de Ultra Alta Temperatura (UHT), a AHP não altera o sabor do produto, nem a textura ou o valor nutricional (ALL NATURAL FRESHNESS), mas a pressão elevada pode causar alguns efeitos sobre as características do leite, como a redução do tamanho das micelas de gordura, a desnaturação de proteína do soro do leite, o aumento da solubilidade do cálcio e mudança de cor (BRODY; MORRIS; WICKER, 2007). Foi demosntrado que a aplicação de APH produz melhores resultados quando combinado com processos térmicos (BRODY; MORRIS; WICKER, 2007).

\section{CONCLUSÃO}

O leite é um alimento benéfico do ponto de vista nutricional devido à sua composição química e é amplamente consumido em todo o mundo. Por isso é importante que a microbiota do leite seja conhecida e controlada, uma vez que diversos microrganismos patogênicos aos seres humanos podem ser veiculados por produtos lácteos de baixa qualidade. Nesse sentido os métodos de conservação são fundamentais para diminuir, ou até mesmo eliminar, esses microrganismos do leite, proporcionando melhor qualidade nutricional ao produto, maior vida de prateleira e maior segurança alimentar aos consumidores.

\section{REFERÊNCIAS}

ALL NATURAL FRESHNESS. HPP solutions for the dairy industry. Disponível em: http://allnaturalfreshness.com/hpp-solutions-for-the-dairy-industry/ Acesso em: 08 fev. 2014. 
ÁLVARES, J. G.; BERNARDES, P. R.; NETTO, V. N. Políticas para o agronegócio do leite: conquistas e desafios. In: O agronegócio do leite e políticas públicas para o seu desenvolvimento sustentável. VILELA, D. et al. Juiz de Fora: Embrapa Gado de Leite, 2002. 546 p.

ANAL, A. K.; SINGH, H. Recent advances in microencapsulation of probiotics for industrial applications and targeted delivery. Food Science \& Technology, v. 18, n. 5, p. 240-251, 2007.

ARCURI, E. F. et al. Qualidade microbiológica do leite refrigerado nas fazendas. Arquivo Brasileiro de Medicina Veterinária e Zootecnia, v.58, n.3, p.440446, 2006.

BAERT, L.; DEBEVERE, J.; UYTTENDAELE, M. The Efficacy of Preservation Methods to Inactivate of Foodborne Viruses. International Journal of Food Microbiology, v. 131, p. 83-94, 2009.

BEHMER, M. L. A. Tecnologia do leito. 13 ed. São Paulo: Ed. Noel, 1999, 320 p..

BOZO, G. A. et al. Adequação da contagem de células somáticas e da contagem bacteriana total em leite cru refrigerado aos parâmetros da legislação. Arq. Bras. Med. Vet. Zootec., v. 65, n. 2, p. 589-594, 2013.

BRASIL, 1952. Ministério da Agricultura, Pecuária e Abastecimento. Regulamento da Inspeção Industrial e Sanitária de Produtos de Origem Animal (RIISPOA). Aprovado pelo decreto $\mathrm{n}^{\circ} 30.691$, de 20 de março de 1952. Brasília, 1952.

BRASIL, 2008. Agência Nacional de Vigilância Sanitária. Lista de alegações de propriedade funcional aprovadas. Brasília, 2008. Disponível em: $<$ http://www.anvisa.gov.br/alimentos/comissoes/ tecno_lista_alega.htm>. Acesso em 03 de fevereiro de 2014.

BRASIL, 2011. Ministério Da Agricultura, Pecuária e Abastecimento. Instrução Normativa ${ }^{\circ} 62$ de 29 de dezembro de 2011. Regulamentos Técnicos de Produção, Identidade e Qualidade do Leite tipo A, do Leite Pasteurizado e do Leite Cru Refrigerado e o Regulamento Técnico da Coleta de Leite Cru Refrigerado e seu Transporte a Granel. Diário Oficial da União, seção 1, dezembro de 2011. Disponível em: http://sistemasweb.agricultura.gov.br/ sislegis/ action/detalhaAto.do? method $=$ co nsultarLegislaca-
oFederal

BRITO, M. A. V. P.; ARCURI, E. F.; BRITO, J. R. F. Testando a qualidade do leite. In: Avanços tecnológicos para o aumento da produtividade leiteira. 2000, Juiz de Fora. Anais... Juiz de Fora: Embrapa Gado de Leite, p. 83-94, 2000.

BRITO, J. R. F.; BRITO, M. A. V. P.; VERNEQUE, R. S. Contagem bacteriana da superfície de tetas de vacas submetidas a diferentes processos de higienização, incluindo a ordenha manual com participação do bezerro para estimular a descida do leite. Revista Ciência Rural, v. 30, n. 5, p. 847-850, 2000.

BRITO, M. A. V. P. et al. Avaliação da sensibilidade da ultura de leite do tanque para isolamento de agentes contagiosos da mastite bovina. Pesq. Vet. Bras., v. 18, n. 1, p. 39-44, 1998.

BRODY, A. L.; MORRIS, C.; WICKER, L. Non-Thermal Food Processing/Preservation Technologies: A Review with Packaging Implications. Packaging Technology and Science, v. 20, p. 275-286, 2007.

BULLETIN of the International Dairy Federation. Payment systems for ex-farm milk. Brussels: International Dairy Federation. Bulletin 403/2006, 2006. $106 \mathrm{p}$.

CONSIDINE, K. M. et al. High-pressure processing-effects on microbial food safety and food quality. Fems Microbiol Lett, v. 281, p. 1-9, 2008.

COSTA, M. L. et al. Purificación y caracterización de proteasas de Pseudomonas fluorescens y sus efectos sobre las proteínas de la leche. Archivos Latinoamericanos de Nutrición, v. 52, n. 2, 2002. Disponível em: < http://www.scielo. org.ve/scielo.php?script=sci_arttext\&pid=S0004$-06222002000200007 \&$ lang $=p t>$. Acessado em: 05 de fevereiro de 2014.

CLETUS KURTZMAN, J. W.; FELL, J.; BOEKHOUT, T. The Yeasts: A Taxonomic Study. 5 ed. Amsterdam: Elsevier Science, v.1 2011, p.55.

DÜRR, J. W. Segurança alimentar e qualidade do leite. In: O agronegócio do leite e políticas públicas para o seu desenvolvimento sustentável. VILELA, D. et al. Juiz de Fora: Embrapa Gado de Leite, 2002. $546 \mathrm{p}$. 
ETTER, E., et al. Risk analysis and bovine tuberculosis, a re-emerging zoonosis. Annals of the New York Acadamy of Sciences, v. 1081, p. 61-73. Disponível em <http://dx.doi.org/10.1196/ annals.1373.006> .Acessado em: 28 de janeiro de 2014.

EVANGELISTA, J. Tecnologia de Alimentos. Rio de Janeiro, São Paulo: Atheneu, 1987.

FONSECA, L. F. L. Qualidade do leite e sua relação com equipamento de ordenha e sistema de resfriamento. In: SIMPÓSIO INTERNACIONAL SOBRE QUALIDADE DO LEITE 1., 1998, Curitiba. Anais... Curitiba: [s.n.], 1998. p. 54-56.

FOSCHIERA, J. L. Indústria de laticínios. Industrialização do leite, análises e produção de derivados. Porto Alegre: Ed. Suliani, 2004, 88 p.

FRANCO, B. D. G. M. et al. Microbiologia dos Alimentos. São Paulo: Ed. Atheneu, 2008, 196 p.

GILL, H. S. Probiotics to enhance anti-infective defences in the gastrointestinal tract. Best Practice \& Research Clinical Gastroenterology, v. 17, n. 5, p. 755-773, 2003.

GOMES, A. M. P.; MALCATA, F. X. Bifidobacterium spp. and Lactobacillus acidophilus: biological, biochemical, technological and therapeutical properties relevant for use as probiotics. Trends in Food Science \& Technology, v. 10, n. 4-5, p. 139-157, 1999.

GUERREIRO, P. K. et al. Qualidade microbiológica de leite em função de técnicas profiláticas no manejo de produção. Ciênc. agrotec., Lavras, v. 29, n. 1, p. 216-222, 2005.

GUIDO, E. S. et al. Uma abordagem da extensão universitária na melhoria da qualidade do leite na cadeia produtiva do município de Barbosa Ferraz (Paraná). B.CEPPA, v.2 8, n. 2, p. 303-312, 2010.

HARMON, R. J. Physiology of Mastitis and Factors Affecting Somatic Cell Counts. Journal of Dairy Science, v. 77, p. 2103-2112, 1994.

HILLERTON, E. J. et al. Evaluation of Bovine Teat Condition In Commercial Dairy Herds: Infectious Factors And Infections. In: Proceedings of the 2 nd International Symposium on Mastitis and Milk Quality. 2001, Compton, United King. Anais... United King : Institute for Animal Health. Compton, United
King, 2001.

JAY, J.M. Microbiologia de Alimentos. Porto Alegre: Artmed, 2005, 6 ed., 712p.

KAZWALA, R. R. et al. Isolation of Mycobacterium species from raw milk of pastoral cattle of the Southern Highlands of Tanzania. Tropical Animal Health and Production, v. 30, p. 233-239, 1998.

KAZWALA, R. R. et al. Isolation of Mycobacterium bovis from human cases of cervical adenitis in Tanzania, a cause for concern? International Journal of Tuberculosis and Lung Diseases, v. 5, p. 87-91, 2001.

KOOPMANS, M.; DUIZER, E. Foodborne Viruses: An Emerging Problem. International Journal of Food Microbiology, v. 90, p. 23-41, 2004.

LAVEN, R. A.; ASHMORE, A.; STEWART, C. S. Escherichia coli in the rumen and colon of slaughter cattle, with particular reference to E. coli O157. Veterinary Journal, v. 165, n. 1, p. 78-83, 2003.

LIN, S. et al. Identification of contamination sources of Bacillus cereus in pasteurized milk. International Journal of Food Microbiology, v. 43, p. 159 - 171, 1998.

MAZIERO, M. T. et al. Incidência e avaliação da atividade lipolítica e proteolítica de Bacillus cereus em leite UHT. PUBVET, v. 5, n. 27, Ed. 147, art, 1174, 2011.

MORAES, C. R. Qualidade bacteriológica de leite bovino de mistura, in natura e beneficiado, e detecção sorológica de Brucelose em rebanhos da Região Metropolitana de Porto Alegre. 2005, 78 f. Dissertação (Mestrado em Microbiologia Agrícola e do Ambiente) - Universidade Federal do Rio Grande do Sul, Porto Alegre, 2005.

MHONE, T. A.; MATOPE, G.; PETRONELLA, T. S. Aerobic bacterial, coliform, Escherichia coli and Staphylococcus aureus counts of raw and processed milk from selected smallholder dairy farms of Zimbabwe. International Journal of Food Microbiology, v. 151, p. 223-228, 2011.

OLIVEIRA, C. A. F.; FONSECA, L. F. L.; GERMANO, P. M. L. Aspectos relacionados à produção que influenciam a qualidade do leite. Higiene Alimentar, v. 13, n. 62, p. 10-13, 1999. 
ORDOÑEZ, J. A. Tecnologia de alimentos. São Paulo: Ed. Artmed, 2005, v. 1 e 2.

PELCZAR, M. J. J.; CHAN, E. C. S.; KRIEG, N. R. Microbiologia: conceitos e aplicações. 2 ed. São Paulo: Makron Books, 1997, v. 2.

RADOSTITS, O. M.; LESLIE, K. E.; FETROW, J. Herd Health: Food Animal Production Medicine. Philadelphia: Ed. Sauders, 1994. 233 p.

REZER, A. P. S. Avaliação da Qualidade Microbiológica e Físico-Química do leite UHT integral comercializado no Rio Grande do Sul. 2010, 73 f. Dissertação (Mestrado em Ciência e Tecnologia deAlimentos) - Universidade Federal de Santa Maria, Santa Maria, 2010.

RIVAS, E. O. Pulsed Eletric Fields (PEF): Milk Pasteurization. Encyclopedia of Agricultural, Food and Biological Engineering. 2. ed. 2010.

SANTANA, E. H. W. et al. Milk contamination in different points of the dairy process. Mesophilic, psychrotrophic and proteolytic. Semina: Ciências Agrárias, Londrina, v. 25, n. 4, p. 349-358, 2004.

SANTOS, M. V.; FONSECA, L. F. L. Estratégias para Controle de Mastite e Melhoria da Qualidade de Leite. Pirassununga: Ed. Manole, 2007. 314 p.

SCHUKKEN, Y. H. et al. Monitoring udder health and milk quality using somatic cell counts. Veterinary Research, v. 34, p. 579-596, 2003.

SHAH, R. C.; WADHER, B. J.; REDDY, B. G. L. Incidence and characteristics of Bacillus cereus isolated from Indian foods. Journal of food science and technology, v. 33, n. 03, p. 249-50, 1996.

SILVA, C. G. Detecção Rápida de Psicrotróficos em Leite e Monitoramento de Listeria spp no Ambiente de Processamento de Laticínios. 2006, 33 f. Dissertação (Mestrado em Ciência e Tecnologia de Alimentos) - Universidade Federal Rural do Rio de Janeiro, Rio de Janeiro, 2010.

SILVA, N.; JUNQUEIRA, V. C. A.; SILVEIRA, N. F. A. Manual de métodos de análise microbiológica de alimentos. 3 ed. S; ao Paulo: Varela, 2007. 317 p.

SOUZA, G.N. et al.Variação da contagem de células somáticas em vacas leiteiras de acordo com patógenos da mastite. Arquivo Brasileiro de Medicina Vete- rinária e Zootecnia, v. 61, n. 5, p. 1015-1020, 2009.

SPANAMBERG, A. et al. Diversity and enzyme production by yeasts isolated from raw milk in southern Brazil. Acta Scientiae Veterinariae, v. 32, n. 3, p. 195-199, 2004.

TEBALDI, V. M. R. et al., Isolamento de coliformes, estafilococos e enterococos de leite cru provenientes de tanques de refrigeração por expansão comunitários: identificação, ação lipolítica e proteolítica. Ciênc. Tecnol. Aliment., Campinas, v. 28, n. 3, p. $753-760,2008$.

TRONCO, V. M. Manual para Inspeção de Qualidade do Leite. Santa Maria: Ed. UFSM, 2010. 203 p.

VAN KESSEL, J. S. et al. Effects of ruminal and postruminal infusion of starch hydrolysate or glucose on the microbial ecology of the gastrointestinal tract in growing steers. Journal of Animal Science, v. 80, n. 11, p. 3027-3034, 2002.

VARNAM, A. H.; SUTHERLAND, J. P. Leche y productos lácteos. Zaragoza: Ed. Acribia, 1995. 452p.

VASCONCELLOS, S. A. Principais Zoonoses transmitidas pelo leite. Situação Atual. In: Perspectivas e Avanços da Qualidade do Leite no Brasil. MESQUITA, A. J.; DÜRR, J. W; COELHO, K. O. Goiânia: Ed. Talento, 2006. 352p.

VEGA-MERCADO, H. et al. Pulsed Electric Fields in Food Preservation. Handbook of Food Preservation, 2. ed, p. 783-813, 2007.

WALSTRA, P.; WOUTERS, J. T. M; GEUTERS, T. J. Dairy Science and Technology. Boca Ratón: Ed. CRC Press, 2006. 787 p.

Disponível em: <http://books.google.com.br/ books? $\mathrm{id}=$ qxdmN8JoW- $4 \mathrm{C} \&$ printsec $=$ frontcover $\& \mathrm{dq}=$ WALSTRA $\& \mathrm{hl}=\mathrm{ptBR} \& \mathrm{ei}=\mathrm{yn}>$. Acesso em: 20/06/2013.

WALKING-RIBEIRO, M.; et al. Microbial inactivation and shelf life comparison of 'cold' hurdle processing with pulsed electric fields and microfiltration, and conventional thermal pasteurization in skim milk. International Journal of Food Microbiology. v. 144, p. 379-386, 2011.

ZENI, M. T. et al. Influência dos microrganismos 
psicrotróficos sobre a qualidade do leite refrigerado para produção de UHT. Unoesc \& Ciência ACET v. 4, n. 1, 2013. Disponível em: <http://editora.unoesc. edu.br/index.php/acet/article/view/2111>. Acesso em: $21 / 06 / 2013$. 